\title{
Altenusin, a Nonsteroidal Microbial Metabolite, Attenuates Nonalcoholic Fatty Liver Disease by Activating the Farnesoid X Receptor
}

\author{
Zhihui Zheng, Zanmei Zhao, Shuqiang Li, Xinhua Lu, Mengxi Jiang, Jie Lin, Yunqi An, \\ Yang Xie, Meishu Xu, Wenbin Shen, Grace L. Guo, Yixian Huang, Song Li, Xuexia Zhang, \\ and Wen Xie \\ Center for Pharmacogenetics and Department of Pharmaceutical Sciences (Zh.Z., Za.Z., M.J., Y.A., Y.X., M.X., Y.H., S.L., W.X.) \\ and Department of Pharmacology and Chemical Biology (W.X.), University of Pittsburgh, Pittsburgh, Pennsylvania; New Drug \\ Research and Development Center, North China Pharmaceutical Group, Shijiazhuang, Hebei, China (Zh.Z., X.L., J.L., W.S., X.Z.); \\ Occupational Disease Department, Peking University Third Hospital, Beijing, China (Za.Z., S.L.); and Department of Pharmacology \\ and Toxicology, School of Pharmacy, Rutgers University, Piscataway, New Jersey (G.L.G.)
}

Received March 15, 2017; accepted July 7, 2017

\section{ABSTRACT}

Nonalcoholic fatty liver disease (NAFLD) is a prevalent chronic liver disease. The incidence of NAFLD has increased steadily due to its close association with the global epidemic of obesity and type 2 diabetes. However, there is no effective pharmacological therapy approved for NAFLD. Farnesoid $X$ receptor (FXR), a member of the nuclear receptor subfamily, plays important roles in maintaining the homeostasis of bile acids, glucose, and lipids. FXR agonists have shown promise for the treatment of NAFLD. In this study, we report altenusin (2076A), a natural nonsteroidal fungal metabolite, as a novel selective agonist of FXR with an $\mathrm{EC}_{50}$ value of $3.2 \pm 0.2 \mu \mathrm{M}$. Administration of $2076 \mathrm{~A}$ protected mice from high-fat diet (HFD)induced obesity by reducing the body weight and fat mass by
$22.9 \%$ and $50.0 \%$, respectively. Administration of $2076 \mathrm{~A}$ also decreased the blood glucose level from $178.3 \pm 12.4 \mathrm{mg} / \mathrm{dl}$ to $116.2 \pm 4.1 \mathrm{mg} / \mathrm{dl}$ and the serum insulin level from $1.4 \pm$ $0.6 \mathrm{ng} / \mathrm{dl}$ to $0.4 \pm 0.1 \mathrm{ng} / \mathrm{dl}$. Moreover, 2076A treatment nearly reversed HFD-induced hepatic lipid droplet accumulation and macrovesicular steatosis. These metabolic effects were abolished in FXR knockout mice. Mechanistically, the metabolic benefits of $2076 \mathrm{~A}$ might have been accounted for by the increased insulin sensitivity and suppression of genes that are involved in hepatic gluconeogenesis and lipogenesis. In summary, we have uncovered a new class of nonsteroidal FXR agonist that shows promise in treating NAFLD and the associated metabolic syndrome.

\section{Introduction}

Farnesoid X receptor (FXR, or NR1H4), a member of the nuclear receptor subfamily, is highly expressed in the liver, intestine, kidney, and adrenal gland (Forman et al., 1995). Once activated, FXR binds to the FXR response elements to regulate target gene transcription. Bile acids are the endogenous FXR ligands (Makishima et al., 1999; Parks et al., 1999; Wang et al., 1999). When activated by bile acids, FXR stimulates the expression of small heterodimer partner in the liver and

This work was supported by National Institutes of Health [Grant HD073070]; National Mega-Project for Innovative Drugs (China) [Grant 2012ZX09301002-003]; and National Natural Science Foundation of China [Grant 81173137]. W.X. is also supported by the Joseph Koslow Endowed Chair Professorship from the University of Pittsburgh School of Pharmacy.

The authors declare no conflicts of interest.

Zh.Z. and Za.Z. contributed equally to this work.

https://doi.org/10.1124/mol.117.108829. executes a negative feedback regulation on the synthesis of bile acids by inhibiting the rate-limiting enzyme cholesterol$7 \alpha$-hydroxylase and increasing the expression of bile salt export protein to maintain the homeostasis of bile acids and cholesterol (Goodwin et al., 2000; Lu et al., 2000).

FXR has been reported to have multiple roles in the pathogenesis of metabolic disorders. Previous studies showed that the FXR knockout (KO) mice exhibited elevated plasma levels of cholesterol and triglycerides and excessive accumulation of fat in the liver (Sinal et al., 2000; Lambert et al., 2003; Schmitt et al., 2015). FXR deficiency also led to impaired glucose tolerance and insulin sensitivity (Ma et al., 2006). Furthermore, hepatic overexpression of constitutively active FXR lowered blood glucose levels in diabetic $\mathrm{db} / \mathrm{db}$ and wildtype (WT) mice (Zhang et al., 2006). In pharmacological models, treatment with the FXR agonists GW4064 (Liu et al., 2003; Zhang et al., 2006) or 6 $\alpha$-ethyl-chenodeoxycholic

ABBREVIATIONS: 6-ECDCA, $6 \alpha$-ethyl-chenodeoxycholic acid; ADME, absorption, distribution, metabolism, and excretion; CAR, constitutive androstane receptor; CDCA, chenodeoxycholic acid; FXR, farnesoid X receptor; GSIS, glucose-stimulated insulin secretion; GTT, glucose tolerance test; HFD, high-fat diet; ITT, insulin tolerance test; KO, knockout; LBD, ligand-binding domain; NAFLD, nonalcoholic fatty liver disease; PCR, polymerase chain reaction; PPAR, peroxisome proliferator-activated receptor; SREBP-1c, sterol-regulatory-element binding protein-1c; TGR, G-protein-coupled bile acid receptor; UCP, uncoupling protein; WT, wild-type. 
acid (6-ECDCA), a chenodeoxycholic acid (CDCA) derivative (Cipriani et al., 2010; Maneschi et al., 2013), lowered the plasma levels of triglycerides and cholesterol in chow-fed mice, and ameliorated obesity, hepatic steatosis, hyperglycemia, and hyperlipidemia in $\mathrm{db} / \mathrm{db}$ or high-fat diet (HFD)-induced diabetic mice, rats, and rabbits.

Nonalcoholic fatty liver disease (NAFLD) is currently the most prevalent chronic liver disease worldwide (Loomba and Sanyal, 2013). It is estimated that $30 \%$ of patients with NAFLD may progress to nonalcoholic steatohepatitis, the severe form of NAFLD that could further progress to cirrhosis and hepatocellular carcinoma. However, there are no pharmacological therapies approved for NAFLD. The primary therapeutic intervention for patients with NAFLD is weight loss through dietary modification and lifestyle changes (Loomba and Sanyal, 2013). Clearly, there is an unmet need for the therapies of NAFLD.

Because the majority of preclinical data suggested benefits of FXR agonism in improving glucose homeostasis and lipid metabolism in the liver, FXR agonists have been explored as potential therapies for NAFLD ( $\mathrm{Li}$ et al., 2013). Indeed, extensive efforts have been dedicated to the discovery of FXR agonists for more than a decade (Ali et al., 2015). Several classes of FXR agonists, including GW4046 (Maloney et al., 2000; Liu et al., 2003; Zhang et al., 2006), 6-ECDCA (Cipriani et al., 2010; Maneschi et al., 2013; Mudaliar et al., 2013), WAY-362450 (Flatt et al., 2009; Zhang et al., 2009), and Px-102 (a GW4046 derivative) (Gege et al., 2014), have been developed and evaluated for their activities in relieving NAFLD and type 2 diabetes. The 6-ECDCA (also known as obeticholic acid) and Px-102 have entered phase II clinical trials in patients of NAFLD and type 2 diabetes. However, the clinical data showed that a chronic use of steroidal obeticholic acid may produce cholesterol-related side effects (Armstrong and Newsome, 2015; Trivedi et al., 2016). Therefore, FXR ligands with nonsteroidal chemical structures are urgently needed for the verification of proposed hypothesis and therapeutic development.

In this study, altenusin (2076A), a nonsteroidal fungal metabolite (Nakanishi et al., 1995), was discovered as a new class of chemical structure that selectively activates FXR. The 2076A improves lipid and glucose metabolism both in vitro and in vivo. Moreover, treatment of mice with 2076A markedly reversed the pre-existing NAFLD induced by HFD.

\section{Materials and Methods}

Animals, Diet, and Drug Treatment. WT and whole-body FXR $\mathrm{KO}$ male mice in the C57BL/6J background were purchased from The Jackson Laboratory (Bar Harbor, ME). All mice were housed under a standard 12-hour light, 12-hour dark cycle with free access to food and water. The use of mice in this study complied with all relevant federal guidelines and institutional policies. For the HFD model, 6 -week-old male mice were fed with HFD (cat. no. S3282) containing $60 \%$ of total calories from animal fat purchased from Bio-Serv (Frenchtown, NJ) for 16 weeks. When necessary, mice were treated with $2076 \mathrm{~A}$ isolated by North China Pharmaceutical Group in 20\% dimethyl sulfoxide by daily i.p. injections, and the control mice received the vehicle injections. Body composition was analyzed in live mice using EchoMRI-100TM from Echo Medical Systems (Houston, TX).

Transient Transfection and Luciferase Reporter Gene Assay. HEK293T cells were used for transient transfection and luciferase reporter gene assay. For the initial screening, cells cotransfected with pG5-SV40-Luc reporter plasmid, together with the GAL4 chimeric receptor expression plasmids pGAL4-peroxisome proliferator-activated receptor (PPAR) $\alpha$-ligand-binding domain (LBD), pGAL4-PPAR $\delta$-LBD, pGAL4-PPAR $\gamma$-LBD, pGAL4-LXR $\alpha$-LBD, pGAL4-FXR-LBD, pGAL4-RXR-LBD, pGAL4-ER $\alpha$-LBD, pGAL4-GRLBD, pGAL4-RAR $\alpha$-LBD, pGAL4-RAR $\beta$-LBD, pGAL4-RAR $\gamma$-LBD, pGAL4-ROR $\alpha$-LBD, pGAL4-ROR $\beta$-LBD, or pGAL4-ROR $\gamma$-LBD using Lipofectamine 2000 transfection reagent from Invitrogen (Zheng et al., 2010). Ligands were added to the medium 6 hours after the transfection. The firefly luciferase and Renilla luciferase activities were measured after another 24 hours of incubation using Dual-Luciferase Reporter Assay System (cat. no. E1910) from Promega (Madison, WI). Luciferase activities were normalized to Renilla activity. For the subsequent confirmation of FXR activation and testing of constitutive androstane receptor (CAR) activation, cells were cotransfected with plasmids encoding the full-length human FXR or mouse CAR, and the FXRresponsive luciferase reporter gene tk-EcRE-Luc, or the CAR-responsive reporter gene tk-PBRE-Luc. Cells were harvested 24 hours after the drug treatment and measured for luciferase activity. Transfection efficiency was normalized against $\beta$-gal activity derived from the cotransfected pCMX- $\beta$-gal plasmid. Fold inductions were calculated as relative reporter activity compared with the vehicle-treated cells (Gao et al., 2015). The $\mathrm{EC}_{50}$ was measured by dose-response fit sigmoidal nonlinear regression curve of Origin software 7.0 version.

Isolation and Culture of Primary Mouse Hepatocytes. Primary mouse hepatocytes were isolated from 6- to 8-week-old male mice, as previously described (Gao et al., 2015). Briefly, the liver was first perfused with Hanks' buffered salt solution containing $0.5 \mathrm{mM}$ EGTA and $0.1 \mathrm{M}$ HEPES at $5 \mathrm{ml} / \mathrm{min}$ for 5-10 minutes and then perfused with L-15 medium containing $1.8 \mathrm{mM} \mathrm{CaCl}_{2}, 0.1 \mathrm{M} \mathrm{HEPES}$, and $20 \mu \mathrm{g} / \mathrm{ml}$ liberase (Roche, Indianapolis, IN). After perfusion, the dissociated hepatocytes were filtered through $50-\mu \mathrm{m}$ pore mesh and collected by centrifugation at $500 \mathrm{rpm}$ for 3 minutes at $4^{\circ} \mathrm{C}$. Hepatocytes were seeded onto type 1 collagen-coated dishes in William $\mathrm{E}$ medium containing $5 \%$ fetal bovine serum. The medium was changed to HepatoZYME-SFM medium (GIBCO, Grand Island, NY) 2 hours later.

Hepatocyte Glucose Production Assay. Forskolin-stimulated glucose production in the primary mouse hepatocytes was measured, as described (He et al., 2013). Briefly, hepatocytes were plated onto collagen-coated six-well plates at the density of $2 \times 10^{5}$ cells/well. After cells attached for 2 hours, the medium was changed to hepatocyte maintenance medium overnight. The cells were then washed three times with PBS before incubation for 4 hours in the glucose production medium in the presence or absence of $10 \mu \mathrm{M}$ forskolin, and with or without the test compounds. The medium was collected, and glucose was measured using a hexokinase-based glucose assay kit from Sigma-Aldrich (St. Louis, MO). Glucose levels were normalized to the protein concentrations of the cell lysates.

Real-Time Polymerase Chain Reaction Analysis. Total RNA was isolated using the TRIzol reagent from Invitrogen. Reverse transcription was performed with random hexamer primers and Superscript RT III enzyme from Invitrogen. SYBR Green-based real-time polymerase chain reaction (PCR) was performed with the ABI 7300 Real-Time PCR System. The PCR primer sequences are shown in Table 1 . The quantity of mRNA was normalized to the cyclophilin gene.

Glucose and Insulin Tolerance Tests, and Glucose-Stimulated Insulin Secretion Analysis. For the i.p. glucose tolerance test (GTT), mice were fasted for 16 hours before receiving an i.p. injection of $2 \mathrm{~g} / \mathrm{kg}$ glucose, and blood glucose levels were measured using the Accu-Chek II glucometer from Roche Diagnostics via tail vein at the time points of 0 , 15, 30, 60, 90, and 120 minutes. At the same time points, blood samples were also collected from tail vein and centrifuged, and then stored at $-80^{\circ} \mathrm{C}$ for the insulin measurements and glucose-stimulated insulin secretion (GSIS) analysis. For the insulin tolerance test (ITT), mice were fasted for 6 hours before receiving an i.p. injection of insulin at $0.5 \mathrm{U} / \mathrm{kg}$ body weight, and blood glucose levels were measured at the time points of $0,15,30,60,90$, and 120 minutes. 
TABLE 1

Primer sequences for real-time PCR

\begin{tabular}{lll}
\hline \multicolumn{1}{c}{ Genes } & Forward Primer Sequence $\left(5^{\prime}-3^{\prime}\right)$ & Reverse Primer Sequence $\left(5^{\prime}-3^{\prime}\right)$ \\
\hline ACC & TGACAGACTGATCGCAGA & TGGAGAGCCCACACAC \\
aP2 & GATGAAATCACCGCAGACG & ATTGTGGTCGACTTTCCAT \\
BSEP & GGAGATGGCACAGGAGG & GCCCGAGTGCTTCAGCT \\
Cyclophilin & AAGGACAGCCACACCAAC & CCAGAACATGACAAACG \\
CYP7A1 & AGCAACTAAACAACCTGCCA & GTCCGGATATTCAAGGATG \\
FAS & GCTGCGGAAATTCAGGA & AGAGACGTGTCACTCCTGG \\
FOXO1 & TGGACATGCTCAGCAGACATC & TTGGGTCAGGCGTTCA \\
G6Pase & ATGGAGGAAGGATGAACA & TGGGAAAGAGACATAGAA \\
L-FABP & ACCTCATCCAGAAAGGAA & ACAATGTCGCCAATGTCATG \\
MACD & ATTTGGAAAGCTGCTAGTGGA & CATAGCCTCCGAAATCTG \\
PEPCK & CTCACTGACTCGGCTTACG & CCACTGAATGCAGACACTT \\
PGC-1 $\alpha$ & AAACTTGCTAGCGGTCCTCA & TGGCTGGTGCCAGTAAGAG \\
PPAR $\gamma$ & GCCCTTTGGTACTTTATGGA & GCAGCAGGTTGTCTGGATG \\
SHP & TGGGTCCCAAGGAGTATGC & CAGTGATGTCAACGTCTCC \\
SR-B1 & CCTTCAATGACAACGACACCG & CCATGCGACTTGTCAGGCT \\
SREBP1c & ATCGGCGCGAAGCTGTCGG & ACTGTCTTGGTTGTGATGA \\
UCP2 & CTCAGAAAGGTGCCTCCCGA & CTCGCTCCTGGAAGATGGTG \\
UCP3 & CCTACGACATCATCAAGGAGA & TCCAAAGGCAGAGACAAAG \\
\hline
\end{tabular}

Tissue Histology and Plasma Biochemistry. For H\&E staining, tissues were fixed in 10\% paraformaldehyde, embedded in paraffin, sectioned at $5 \mu \mathrm{m}$, and stained with H\&E. For plasma biochemistry, blood samples were collected from mice with heparinized syringes and then centrifuged at $5000 \mathrm{rpm}$ for 8 minutes. Plasma samples were stored at $-80^{\circ} \mathrm{C}$ until further analysis. Plasma levels of triglycerides, total cholesterol, aspartate aminotransferase, and alanine aminotransferase were measured by using assay kits from Stanbio Laboratory (Boerne, TX). Plasma insulin levels were measured by using an assay kit from Crystal Chem (Downers Grove, IL).

Measurement of Liver Triglyceride and Cholesterol Contents. Lipids in the liver were extracted and measured, as described (He et al., 2013). Briefly, approximately $100 \mathrm{mg}$ liver was homogenized with $3 \mathrm{ml}$ T-PER (Pierce, Rockford, IL). The homogenates were used for protein concentration analysis by the Bradford assay from Bio-Rad (Milan, Italy). To measure the triglyceride and cholesterol contents, $100 \mu \mathrm{l}$ tissue extracts were added to $1.6 \mathrm{ml} \mathrm{CHCl} 3: \mathrm{MeOH}(2: 1)$ for 16 hours at $4^{\circ} \mathrm{C}$. At the end of incubation, $200 \mu \mathrm{l} 0.6 \% \mathrm{NaCl}$ was added and the solutions were centrifuged at $2000 \mathrm{~g}$ for 20 minutes. The organic layer was removed and dried, and the resulting pellet was dissolved in $100 \mu \mathrm{l}$ phosphate-buffered saline containing $0.5 \%$ Triton $\mathrm{X}-100$. Triglyceride and cholesterol concentrations were then measured by using assay kits from Stanbio Laboratory.

Western Blotting. For Western blot analysis, tissues and cells were lysed in ice-cold Nonidet P-40 lysis buffer containing a protease inhibitor cocktail from Roche, and then quantified for protein concentrations by a bicinchoninic acid assay kit from Pierce. Protein samples were resolved by electrophoresis on $10 \%$ SDS-polyacrylamide gels. After transfer of proteins to nitrocellulose membranes, the membranes were probed with primary antibodies against total AKT (cat. no. 9272) and phospho-Akt (serine 473) (cat. no. 9271) from Cell Signaling (Beverly, MA). Detection was achieved by using the enhanced chemiluminescence system from Amersham (Piscataway, NJ). The signals were quantified by using the Image $J$ software version 1.47 (http://imagej.nih.gov/ij/).

Molecular Docking. Docking of 2076A into the LBD of FXR was performed using Autodock version 4.2 software from the Scripps Research Institute (La Jolla, CA) (Morris et al., 2009). The crystal structure of human FXR LBD (Protein Data Bank accession code 1OSH) (Downes et al., 2003) was used as the binding protein. The three-dimensional structure of 2076A was built, and the lowest energy conformer was optimized using ChemDraw Ultra 11 from Cambridge Soft (Cambridge, MA). The Lamarckian genetic algorithm was employed for docking simulation. The coordinates of the crystalized ligand fexaramine were chosen as active-site center, and a grid box size of $25 \AA \times 25 \AA \times 25 \AA$ was used. The protein was treated as rigid, whereas $2076 \mathrm{~A}$ was treated as a flexible molecule. Based on the cluster result and the binding energy, the most favorable dock conformation was chosen for further analysis. Illustration of the three-dimensional model was created by using the Pymol software from DeLano Scientific (San Carlos, CA).

Statistical Analysis. Data are expressed as mean \pm S.D. Statistical significance between two groups was determined by unpaired two-tailed Student's $t$ test. For comparison among multiple groups, one-way analysis of variance followed by Dunnett's multiple comparisons test was used. $P$ value $<0.05$ is considered to be statistically significant. Graphs were generated with GraphPad Prism version 5.01 (San Diego, CA).

\section{Results}

2076A is a Selective FXR Agonist. In screening for novel FXR agonists, the GAL4-FXR-LBD chimeric receptor was used to assess the activity of test compounds. Altenusin (2076A) (Fig. 1A), a natural product from North China Pharmaceutical Group's microbial metabolite library, was found to induce the GAL4-responsive luciferase reporter gene activity in a concentration-dependent manner, with an estimated $\mathrm{EC}_{50}$ value of $3.4 \pm 0.2 \mu \mathrm{M}$ (Fig. 1B). The potency and efficacy of 2076A in activating FXR in the same system were similar to those of CDCA $\left(\mathrm{EC}_{50}=3.8 \pm 0.3 \mu \mathrm{M}\right)$, an endogenous bile acid FXR agonist. When tested across a panel of GAL4 fusion of nuclear receptors, 2076A showed little activity on 14 other receptors at $30 \mu \mathrm{M}$, suggesting that $2076 \mathrm{~A}$ selectively activates FXR (Fig. 1C). The agonistic activity of 2076A on FXR was verified by an independent luciferase reporter system using the full-length FXR and the FXRresponsive tk-EcRE-Luc reporter gene (Fig. 1D). The 2076A also had little effect on CAR, which was verified by a reporter system using the full-length mouse CAR and the CAR-responsive tk-PBRE-Luc reporter gene (Fig. 1E).

To further confirm the activation of FXR by 2076A, primary hepatocytes isolated from the WT and FXR KO mice were treated with vehicle, 2076A, or CDCA before being measured for the expression of known FXR-responsive genes. As shown in Fig. 1F, compared with the vehicle, 2076A dosedependently induced the expression of small heterodimer 
A<smiles>COc1cc(O)c(C(=O)O)c(-c2cc(O)c(O)cc2C)c1</smiles>

C

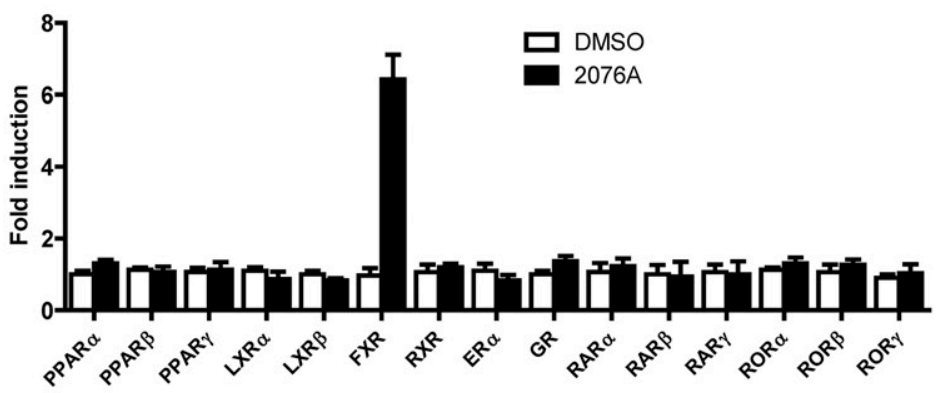

B

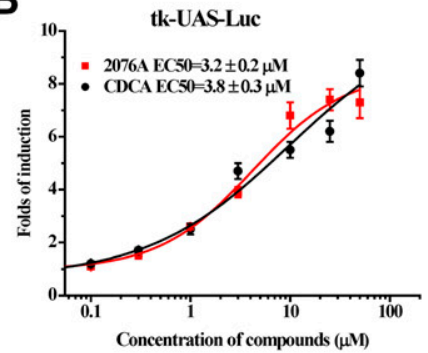

D

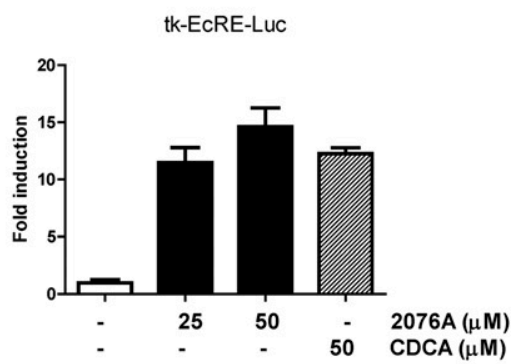

E

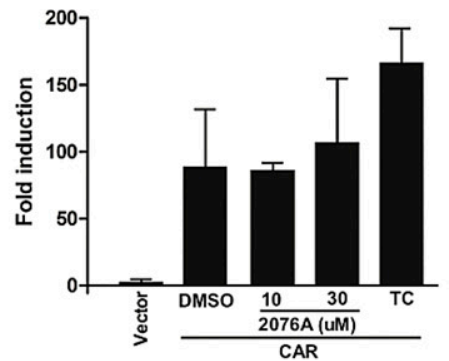

F

SHP
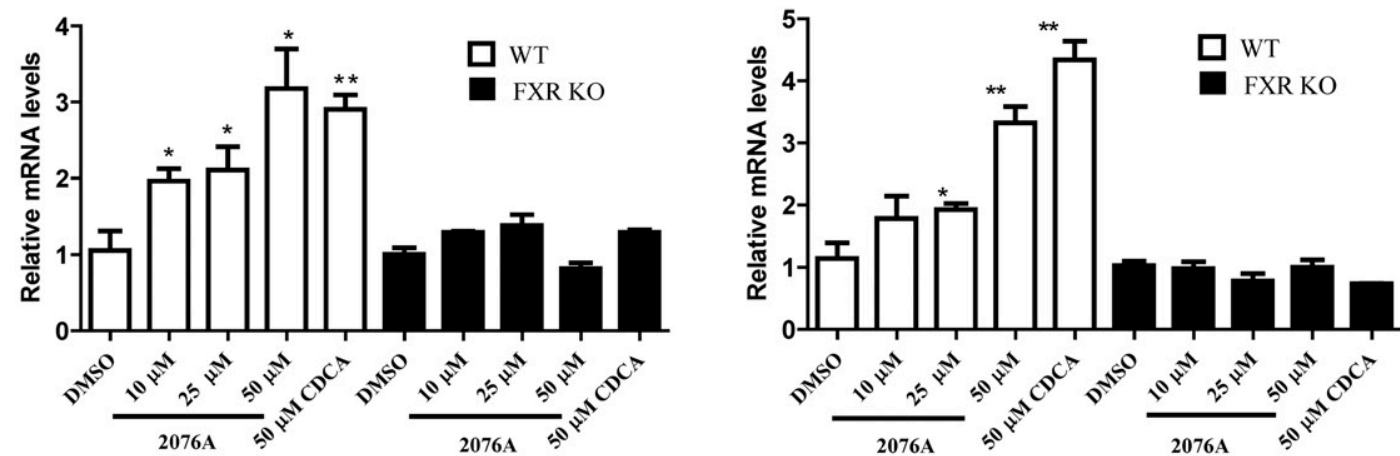

CYP7A1
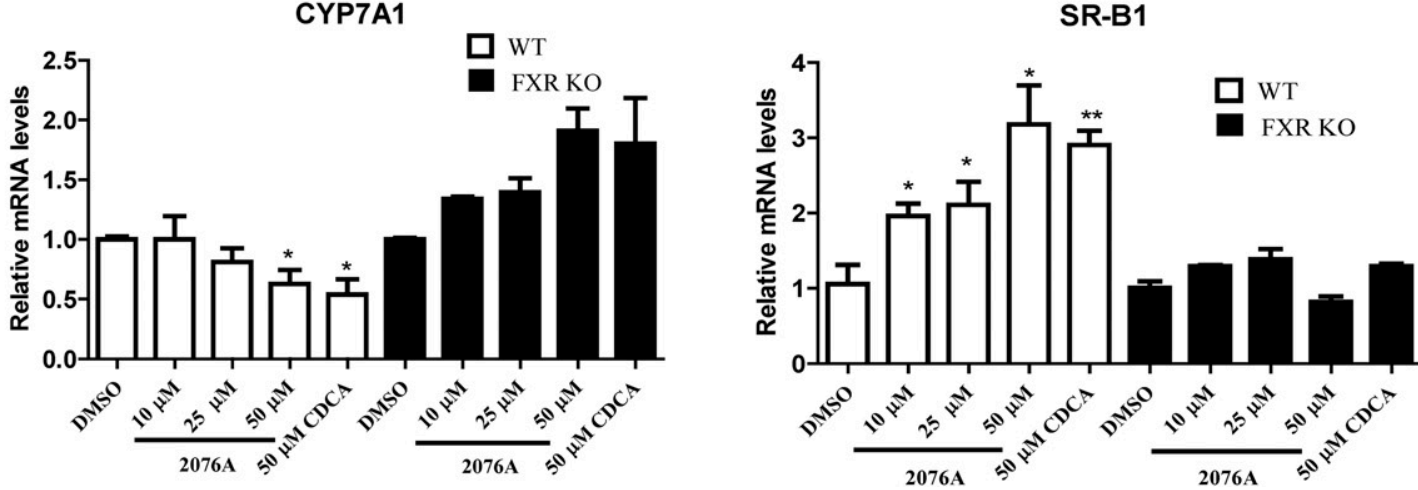

Fig. 1. The 2076A is a selective FXR agonist. (A) Chemical structure of 2076A. (B) Activation of the GAL4-hFXR LBD chimeric receptor by 2076A. Cells were cotransfected with GAL4-hFXR LBD and the GAL4-responisve luciferase report tk-UAS-Luc. The transfected cells were treated with increasing concentrations of 2076A for 24 hours before luciferase assay. (C) The 2076A did not activate GAL4 fusions of 14 other nuclear receptors. (D) Activation of the full-length FXR by 2076A. Cells were cotransfected with FXR and the FXR-responsive tk-EcRE-Luc luciferase report gene. The transfected cells were treated with increasing concentrations of 2076A for 24 hours before luciferase assay. (E) Lack of activation of CAR by 2076A. Cells were cotransfected with the full-length mouse CAR and the CAR-responsive tk-PBRE-Luc luciferase report. The transfected cells were treated with $2076 \mathrm{~A}$ or TCPOBOP for 24 hours before luciferase assay. (F) The expression of FXR-responsive genes in primary hepatocytes isolated from WT and FXR KO mice. The hepatocytes were treated with vehicle or $2076 \mathrm{~A}(10,25$, or $50 \mu \mathrm{M})$ for 24 hours before cell harvesting and real-time PCR analysis; CDCA (50 $\mu \mathrm{M})$ was included as the positive control. The data represent mean \pm S.D. $n=3$ for each group. ${ }^{*} P<0.05 ; * * P<0.01$ compared with the vehicle-treated group. The transfection results represent one of three independent experiments. 
partner, bile salt export pump, and scavenger receptor class B1, three known FXR target genes, and suppressed the expression of cholesterol-7 $\alpha$-hydroxylase, a gene negatively regulated by FXR (Goodwin et al., 2000; Lu et al., 2000), in hepatocytes isolated from WT mice, whereas these responses were abolished in hepatocytes isolated from FXR KO mice.

Computational Docking Analysis of the Binding of 2076A to FXR. To determine whether 2076A can bind to FXR, we performed a molecular docking simulation by using the Autodock 4.2 software and the crystal structure of the human FXR LBD (Downes et al., 2003). In the dominant conformational cluster, the conformation with the lowest binding energy was used to predict the binding mode. As shown in Fig. 2, 2076A fits well into the ligand-binding pocket of FXR. The hydroxyl, methoxy, and carboxyl groups of 2076A were able to establish several hydrogen bond contacts with four amino acids in the ligand-binding pocket, His298, Ser336, Leu352, and Tyr365. In addition to hydrogen bonds, multiple hydrophobic interactions were also observed between 2076A and several amino acids within the pocket, namely Met294, Met332, Phe340, Ile356, and Met369. These results suggested that 2076A can bind to the LBD of FXR to activate FXR.

Treatment with 2076A Leads to Metabolic Benefits in Chow-Fed Mice. We went on to investigate whether 2076A could produce metabolic benefits in vivo. We first treated chow-fed WT mice daily with increasing doses of $2076 \mathrm{~A}(5,10$, $30 \mathrm{mg} / \mathrm{kg}$ ) by i.p. injections for 1 week. As shown in Fig. 3 and at the dose of $30 \mathrm{mg} / \mathrm{kg}$, treatment with $2076 \mathrm{~A}$ lowered the levels of fed and fasting blood glucose and plasma triglycerides. Based on these results, we chose the dose of $30 \mathrm{mg} / \mathrm{kg}$ for the subsequent in vivo experiments. All three doses of $2076 \mathrm{~A}$ had little effect on the body weight, the ratio of liver to body weight, or the plasma levels of alanine aminotransferase and aspartate aminotransferase (data not shown), suggesting that 2076A was well tolerated by mice without noticeable toxicity.

Treatment with 2076A Inhibits HFD-Induced Obesity. To further investigate the metabolic benefit of $2076 \mathrm{~A}$

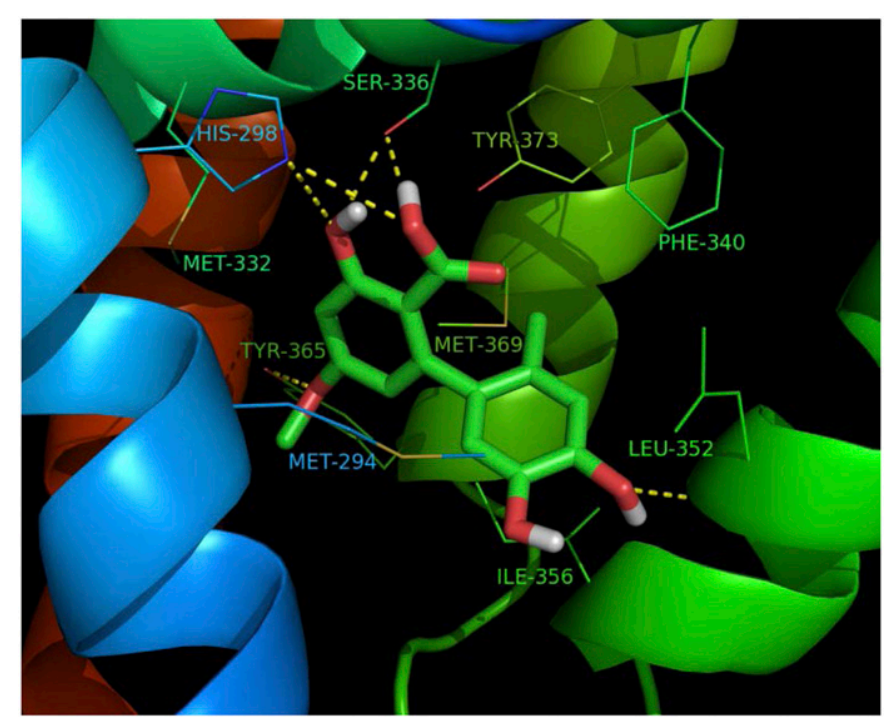

Fig. 2. Computational docking analysis of the binding of $2076 \mathrm{~A}$ to FXR. The docking analysis was based on the crystal structures of human FXR from the Protein Data Bank (PDB identification: 1OSH). The hydrogen bond interactions between 2076A and FXR are shown in yellow dash lines. and its dependence on FXR, we challenged WT and FXR KO male mice with HFD for 16 weeks beginning at the age of 6 weeks, and then treated the mice with $2076 \mathrm{~A}(30 \mathrm{mg} / \mathrm{kg})$ daily by i.p. injections for 3 weeks, during which the mice remained on HFD. The results showed that the average weight of WT mice treated with $2076 \mathrm{~A}$ decreased by $22.9 \%$ compared with their vehicle-treated counterparts without significant difference in food intake (data not shown), but this effect was abolished in FXR KO mice (Fig. 4, A and C). Necropsy showed that the visceral fat mass and subcutaneous fat mass were remarkably lowered in 2076A-treated WT mice, but not in 2076A-treated FXR KO mice (Fig. 4B). Body composition analysis by magnetic resonance imaging further revealed that treatment with $2076 \mathrm{~A}$ reduced the fat mass of WT mice from an average of $17.1 \pm 2.8 \mathrm{~g}$ to $8.5 \pm 4.8 \mathrm{~g}$ (a reduction of approximately 50\%), but had little effect on the lean mass in WT mice (Fig. 4C). These results suggested that the majority of the reduced body weight in 2076A-treated WT mice was accounted for by the decrease of fat mass. Histopathological analysis of the visceral fat by H\&E staining showed that the sizes of adipocytes in 2076A-treated WT mice, but not in 2076A-treated FXR KO mice, were reduced (Fig. 4D).

To understand the mechanism for the metabolic benefit, we analyzed the expression of genes involved in energy expenditure and lipogenesis. Uncoupling proteins (UCPs) are a subgroup of mitochondrial carrier proteins that can affect energy expenditure. UCP2 and UCP3 are two key regulators of mitochondrial energy metabolism (Boss et al., 2000). The expression of UCP2 and UCP3 was significantly increased in the adipose tissue and skeletal muscle of 2076A-treated WT mice, but not the FXR KO mice (Fig. 4E). When the adipose expression of genes involved in adipocyte differentiation and lipogenesis was analyzed, we found the mRNA levels of PPAR $\gamma$ and adipocyte protein 2, two key adipocyte differentiation markers (MacDougald and Lane, 1995), were significantly decreased in 2076A-treated WT mice, but not the FXR KO mice (Fig. 4F). The expression of lipogenic genes acetyl-CoA carboxylase, fatty acid synthase, and sterol-regulatory-element binding protein-1c (SREBP-1c) was downregulated in 2076A-treated WT mice, but not the FXR KO mice (Fig. 4G).

Treatment with 2076A Reverses HFD-Induced Hepatic Steatosis. Next, we examined the effect of $2076 \mathrm{~A}$ on HFD-induced hepatic steatosis. Upon the 19-week HFD feeding and as expected, the vehicle-treated WT mice displayed marked hepatic steatosis, which was supported by both the gross appearance of the liver (Fig. 5A) and histologic analysis by H\&E staining (Fig. 5B). Administration with 2076A for 3 weeks, while the mice remained on HFD, almost completely reversed the lipid droplet accumulation and macrovesicular steatosis in WT, but not in FXR KO mice (Fig. 5B). Compared with the vehicle control, treatment with $2076 \mathrm{~A}$ decreased the liver weight from $1.5 \pm 0.3 \mathrm{~g}$ to $1.1 \pm 0.1 \mathrm{~g}$ in WT mice, but not in FXR KO mice (Fig. 5C). When the lipid contents were analyzed, we found both the hepatic triglyceride (Fig. 5D) and cholesterol (Fig. 5E) contents in 2076A-treated WT mice were reduced to approximately half of the vehicle group levels, and these effects were not seen in 2076A-treated FXR KO mice. These data demonstrated that 2076A could reverse pre-existing hepatic steatosis in a FXR-dependent manner. Treatment of primary mouse hepatocytes with $2076 \mathrm{~A}$ also inhibited oleic acid-induced steatosis in vitro (data not shown). 

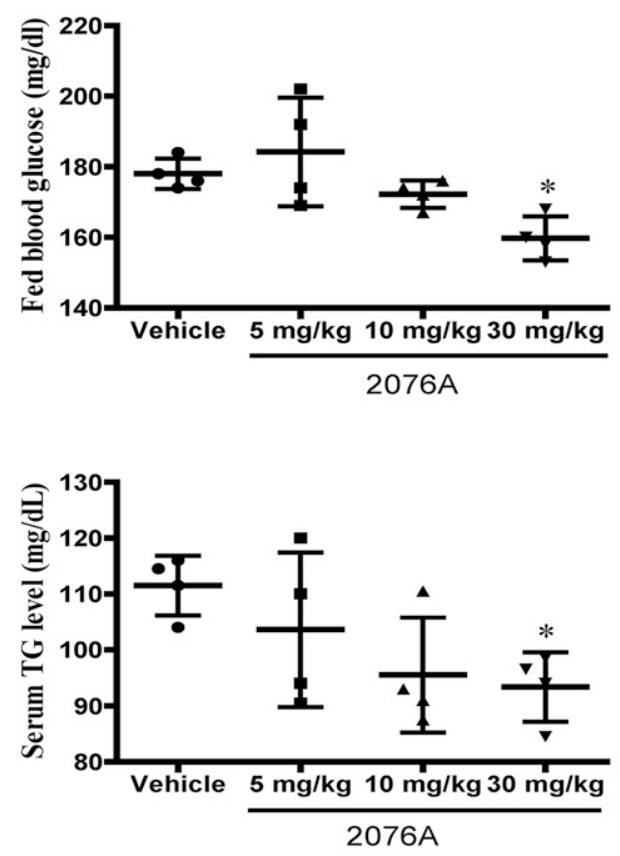
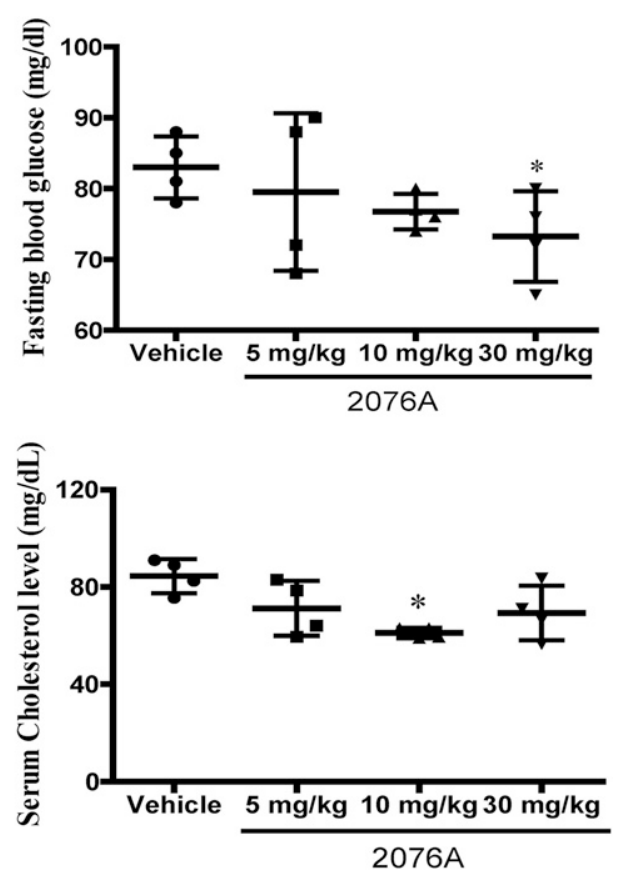

Fig. 3. Treatment with $2076 \mathrm{~A}$ leads to metabolic benefits in chow-fed mice. Eightweek-old WT mice fed on chow diet were treated daily with increasing doses of $2076 \mathrm{~A}$ $(5,10,30 \mathrm{mg} / \mathrm{kg})$ by i.p. injections for 1 week; the fed blood glucose and fasting blood glucose levels were measured. The plasma concentrations of triglyceride and cholesterol were also measured. $n=4$ for each group; $* P<0.05$, compared with the vehicle-treated group.
In understanding the mechanism by which $2076 \mathrm{~A}$ inhibits hepatic steatosis, we found the expression of lipogenic genes MACD, acetyl-CoA carboxylase, fatty acid synthase, SREBP1c, and liver fatty acid-binding protein was all significantly suppressed in the livers of 2076A-treated WT mice, but not in the FXR KO mice (Fig. 5F). Liver fatty acid-binding protein, highly expressed in the hepatocytes, can function as a metabolic sensor by regulating the expression of SREBP-1c, PPAR $\gamma$, and $\mathrm{C} / \mathrm{EBP} \alpha$ (Chen et al., 2013). These results suggested that 2076A inhibits hepatic lipogenesis by suppressing the lipogenic gene expression.

Treatment with 2076A Alleviates HFD-Induced Hyperglycemia, Hyperinsulinemia, and Insulin Resistance. The chronic HFD model is associated with hallmarks of metabolic syndrome, such as hyperglycemia, hyperinsulinemia, and insulin resistance. Indeed, the 19-week HFD feeding in WT mice resulted in hyperglycemia with a fasting blood glucose level of $178.3 \pm 12.4 \mathrm{mg} / \mathrm{dl}$ (Fig. 6A) and hyperinsulinemia with a serum insulin level of $1.4 \pm 0.6 \mathrm{ng} / \mathrm{dl}$ (Fig. 6B). Upon 3-week treatment of 2076A, the plasma levels of glucose and insulin in WT mice were decreased to $116.2 \pm$ $4.1 \mathrm{mg} / \mathrm{dl}$ (Fig. 6A) and $0.4 \pm 0.1 \mathrm{ng} / \mathrm{dl}$ (Fig. 6B), respectively, and these effects were not seen in the FXR KO mice, suggesting that 2076A may have lowered the plasma glucose level by increasing the insulin sensitivity. Treatment with 2076A also lowered the serum level of cholesterol (Fig. 6C), but had little effect on the serum level of triglycerides (Fig. 6D) in WT mice.

To determine the effect of $2076 \mathrm{~A}$ on glucose tolerance and insulin sensitivity, we also performed GTT, ITT, and GSIS tests. Compared with the vehicle-treated groups, treatment of HFD-fed WT mice, but not the HFD-fed FXR KO mice, with 2076A significantly enhanced the ability of mice to clear the exogenous glucose in GTT (Fig. 6E) and improved their response to insulin to dispose glucose in ITT (Fig. 6F). The GSIS results showed that the 2076A-treated WT mice showed attenuated glucose-stimulated insulin secretion (Fig. 6G), consistent with their better performances in GTT and ITT. Treatment with 2076A had little effect on the morphology and volume of the pancreatic islets (data not shown). These results suggested that 2076A alleviates hyperglycemia and hyperinsulinemia, and improves insulin sensitivity in diabetic mice in a FXR-dependent manner.

Treatment with 2076A Sensitizes Insulin Signaling and Inhibits Hepatic Gluconeogenesis In Vitro and In Vivo. To understand the molecular mechanism underlying the antidiabetic effect of 2076A, we investigated the effect of $2076 \mathrm{~A}$ on insulin signaling by measuring the phosphorylation of AKT at Ser473, a phosphorylation site required for downstream propagation of the insulin signaling (Hernandez et al., 2001). In vitro, treatment of primary mouse hepatocytes with $2076 \mathrm{~A}$ in the absence (Fig. 7A) or presence (Fig. 7B) of insulin (100 nM) robustly increased the AKT phosphorylation. In vivo, treatment of WT mice with $2076 \mathrm{~A}$ increased the phosphorylation of AKT in the liver and skeletal muscle, but not in the white adipose tissue (Fig. 7C).

Increased hepatic gluconeogenesis is an important pathogenic event in the development of diabetes (Barthel and Schmoll, 2003), so we next investigated the effect of 2076A on hepatic gluconeogenesis. Treatment of primary mouse hepatocytes with 2076A dose-dependently inhibited forskolininduced glucose production (Fig. 7D). In vivo, treatment with 2076A significantly suppressed the expression of hepatic gluconeogenic genes, including forkhead box protein $\mathrm{O} 1$, phosphoenolpyruvate carboxykinase, glucose-6-phosphatase, and PPAR $\gamma$ coactivator $-1 \alpha$ in WT, but not in FXR KO mice (Fig. 7E).

\section{Discussion}

In this study, we have discovered a new class of nonsteroidal FXR agonist 2076A that exhibits marked metabolic benefits. Administration of 2076A to HFD-induced obese mice resulted in significant reductions in body weight and fat mass, 
A

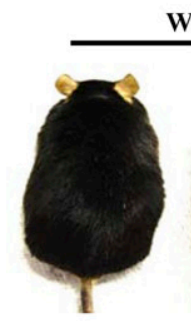

WT

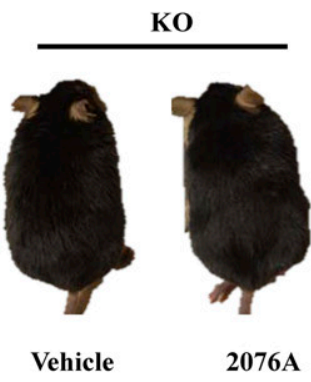

B

Vehicle

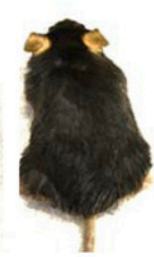

2076A

WT

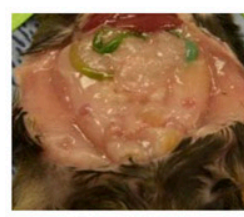

Vehicle

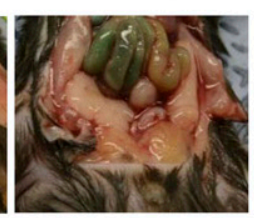

2076A
KO

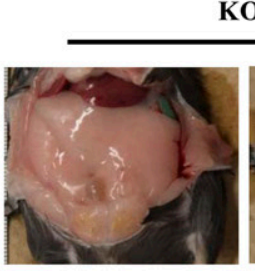

Vehicle

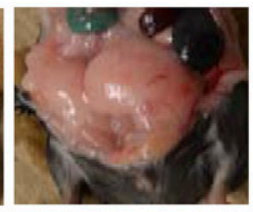

2076A
C

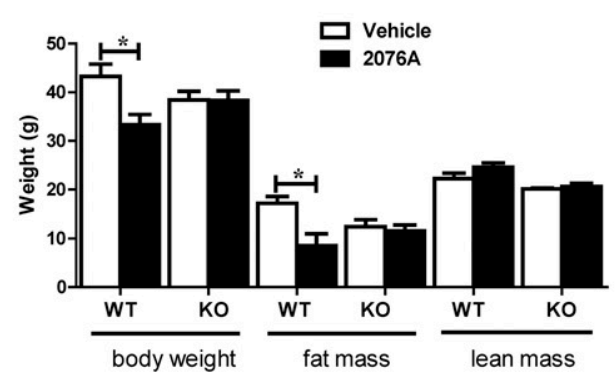

D
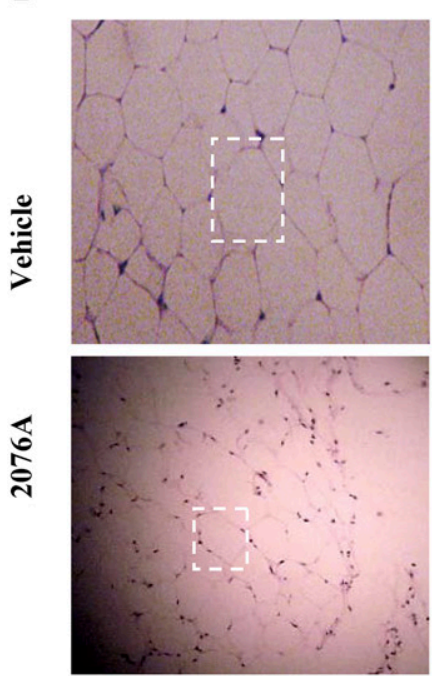

KO
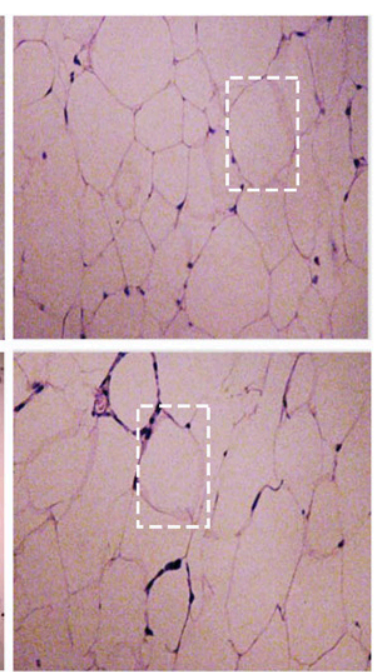

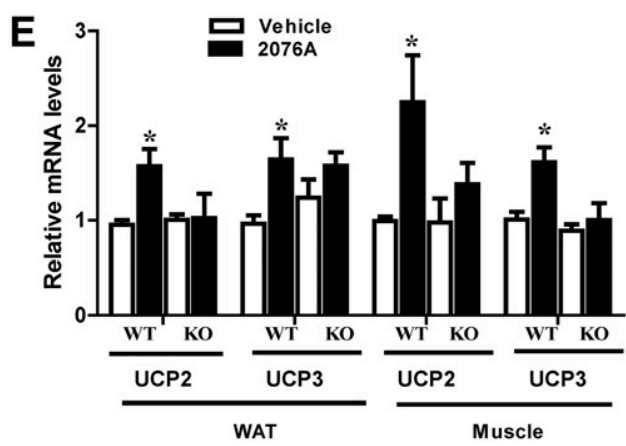

$\mathbf{F}$

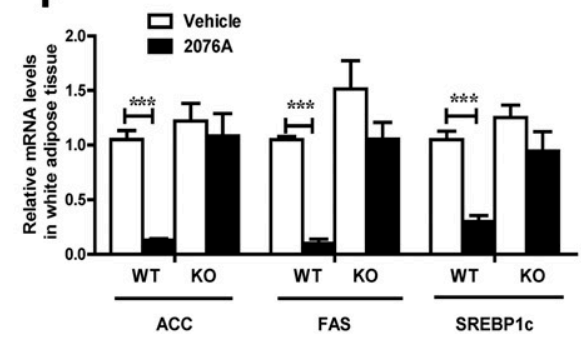

G

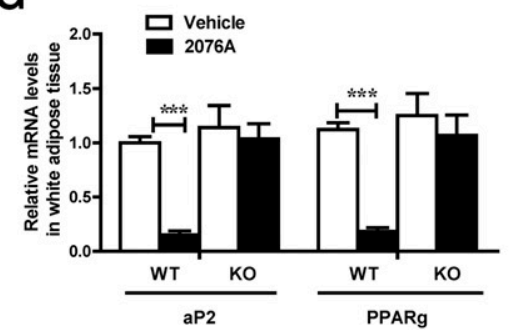

Fig. 4. Treatment with 2076A inhibits HFD-induced obesity. WT ( $n=4$ for each group) and FXR KO mice ( $n=5$ for each group) were fed with HFD for 16 weeks and then treated i.p. with $2076 \mathrm{~A}(30 \mathrm{mg} / \mathrm{kg}$ per day) for 3 weeks. (A) Representative appearance of mice at the end of the experiment. (B) Representative appearance of visceral of mice. (C) Body weight and body composition analysis. (D) Histologic analysis of the visceral fat by H\&E staining. (E-G) The mRNA expression of mitochondrial uncoupling proteins UCPs in the white adipose tissue and skeletal muscle (E), adipocyte differentiation marker genes $(\mathrm{F})$, and lipogenic genes $(\mathrm{G})$ in the visceral fat was measured by real-time PCR. ${ }^{*} P<0.05$; *** $P<0.001$, compared with the vehicle-treated group. Note only the differences between vehicle group and 2076A-treated group within the same genotype (WT or FXR knockout) were compared, so the unpaired two-tailed Student's $t$ test was used. 
A

A WT

Vehicle

2076 A
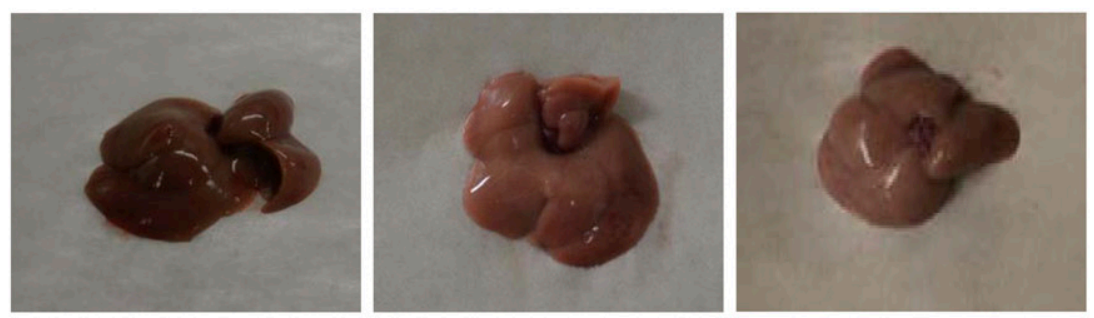

B

WT

KO

Vehicle

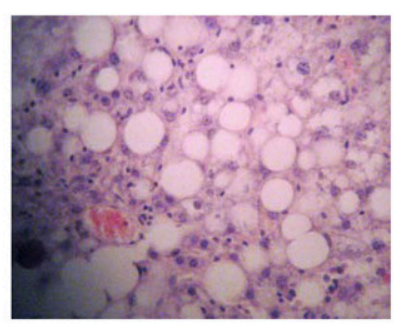

2076A

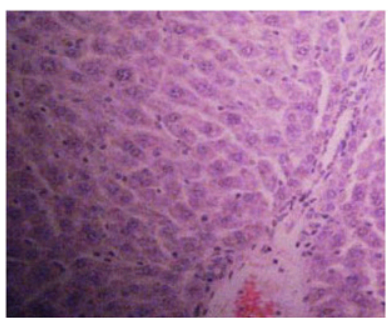

Vehicle

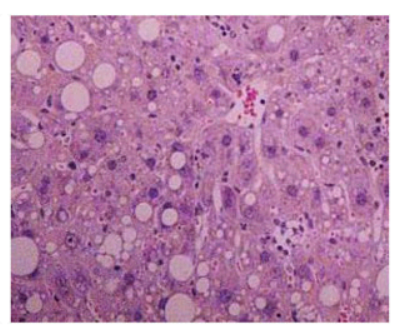

2076A

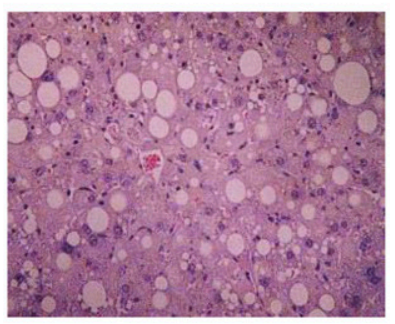

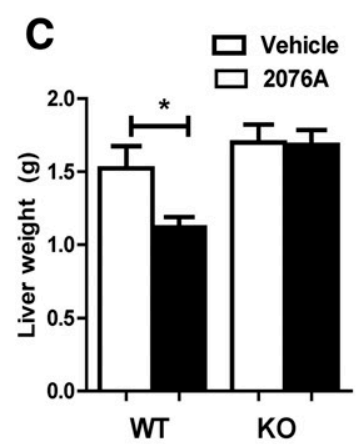
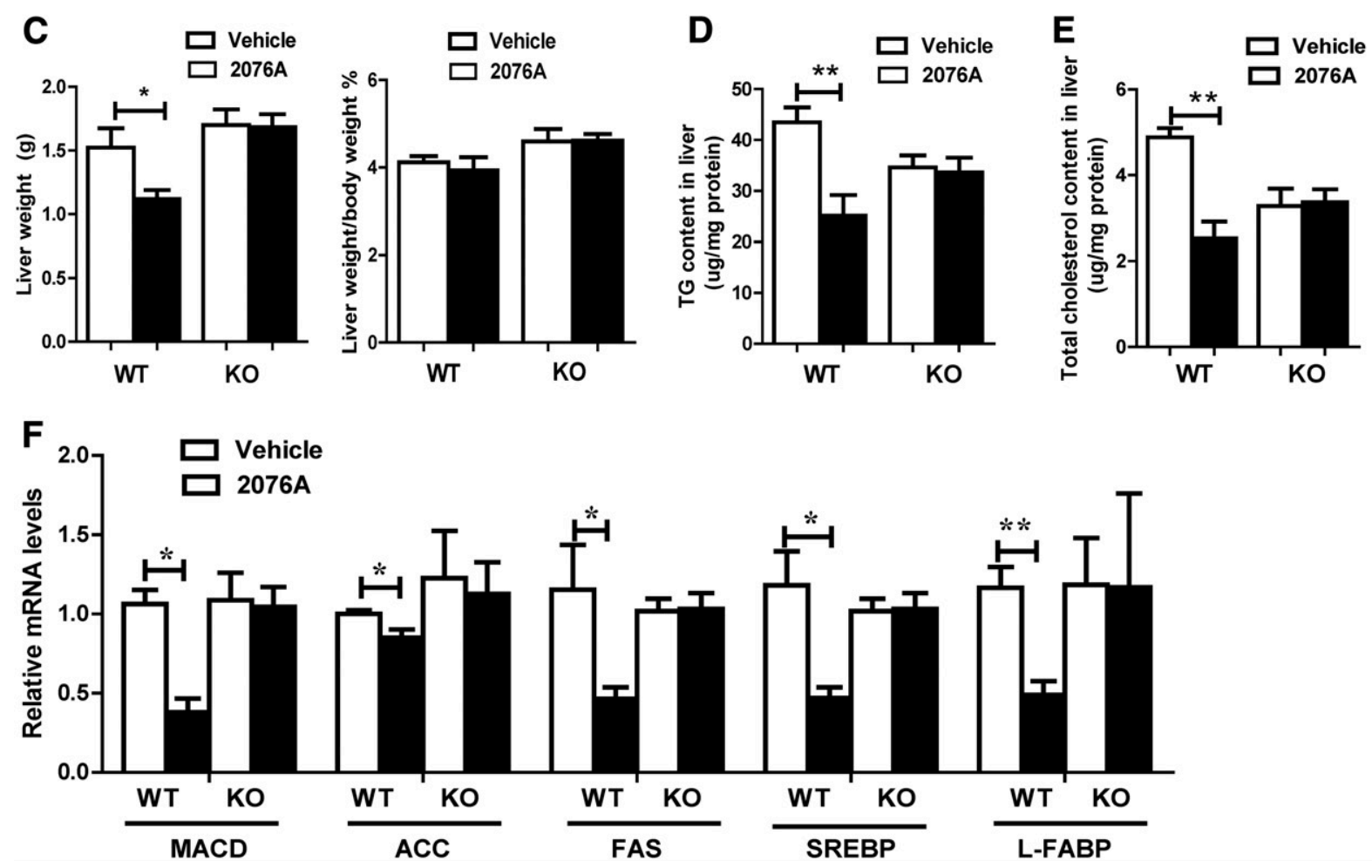

Fig. 5. Treatment with 2076A reverses HFD-induced hepatic steatosis. Mice were the same as described in Fig. 4. (A) Appearance of the livers at the end of the experiment. (B) Histologic analysis of liver sections by H\&E staining. (C) Liver weight (left) and the ratio of liver weight to body weight (right). (D and E) The hepatic levels of triglycerides (D) and cholesterol (E). (F) The hepatic mRNA expression of genes involved in lipogenesis was measured by realtime PCR. WT, $n=4$ for each group; FXR KO, $n=5$ for each group. ${ }^{*} P<0.05$; $* * P<0.01$, compared with the vehicle-treated group.

alleviation of dyslipidemia and insulin resistance, and reversal of hepatic steatosis. The metabolic benefits of $2076 \mathrm{~A}$ were abolished in FXR KO mice, suggesting that FXR is the mediator of these effects.
The 2076A is a fungal metabolite that was originally purified as a weak inhibitor of the myosin light-chain kinase from the endophytic fungal strain Alternaria $s p$. This fungal strain was isolated from the leaves of medicinal plant 
A

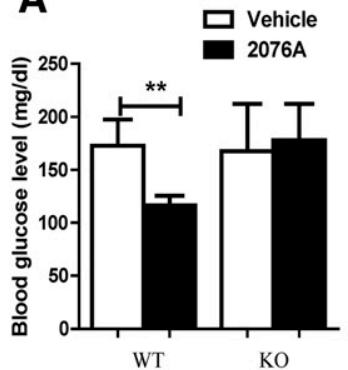

B

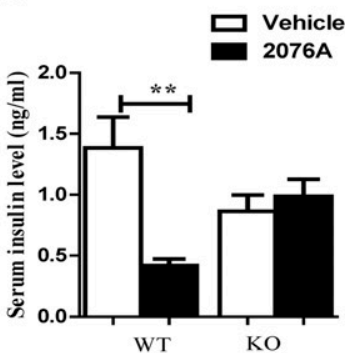

C

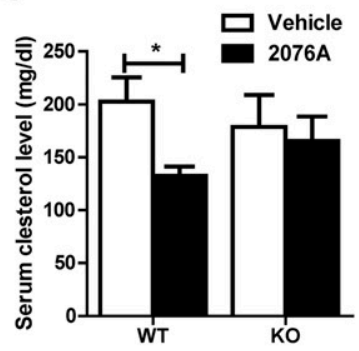

D

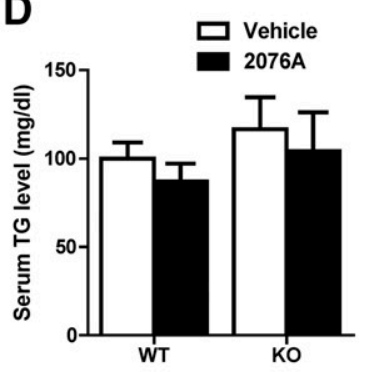

E

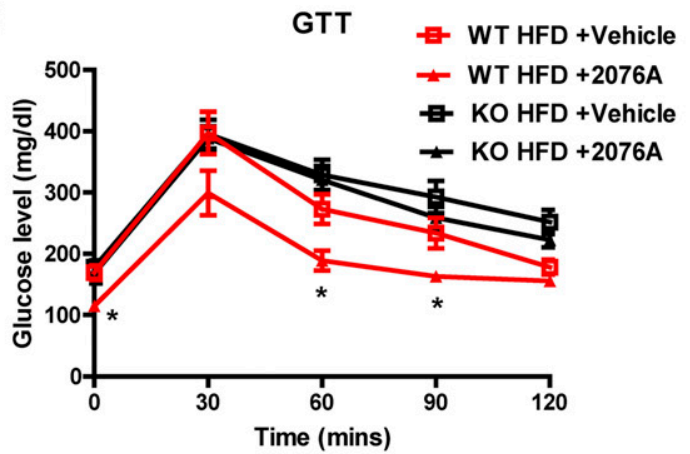

F

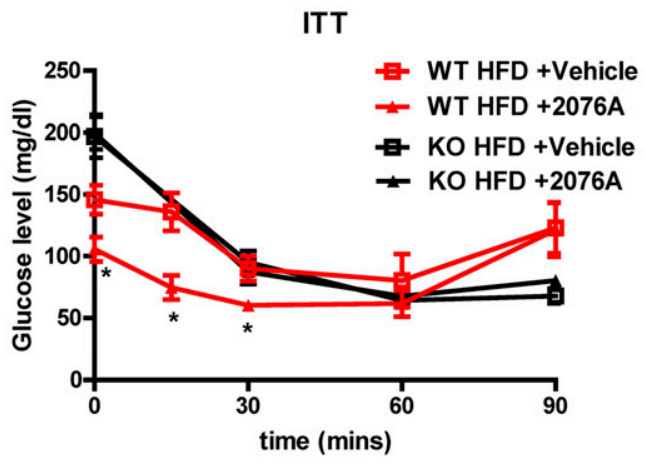

G

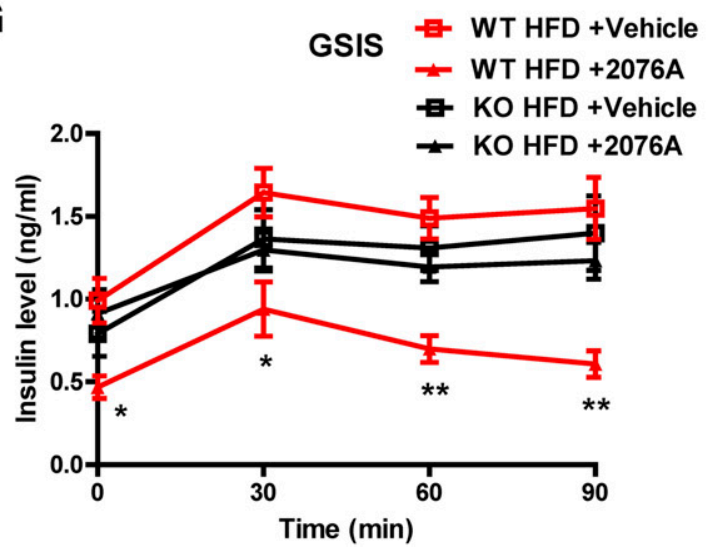

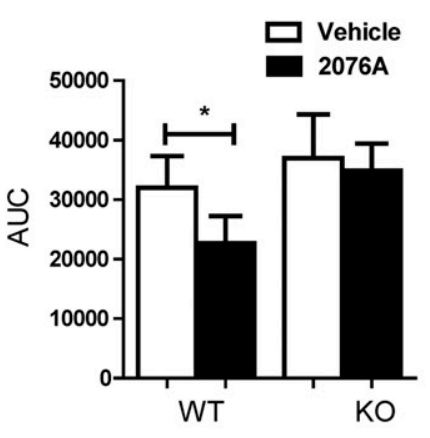
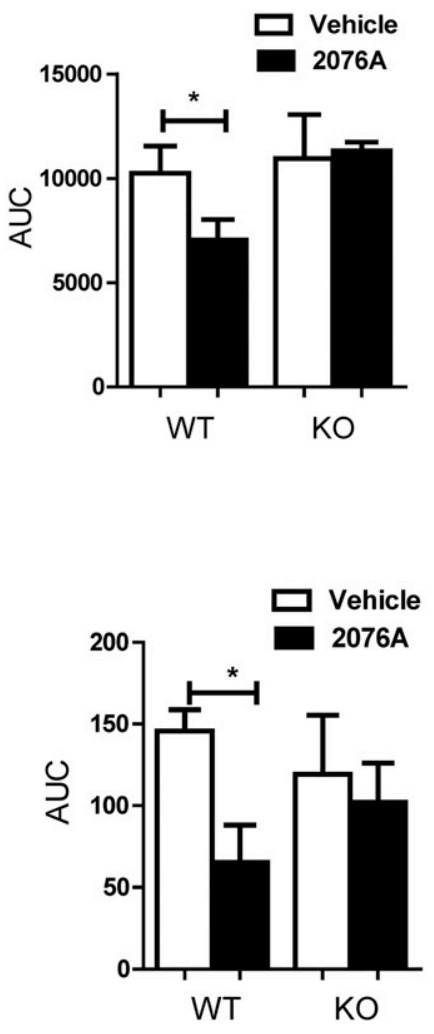

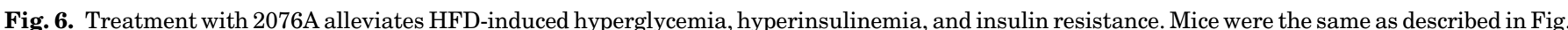

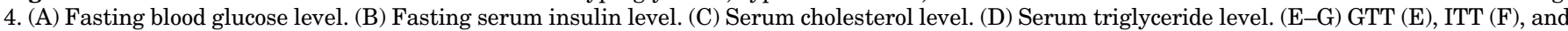

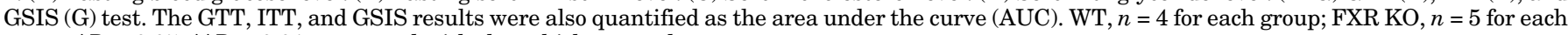
group. ${ }^{*} P<0.05$; ${ }^{*} P<0.01$, compared with the vehicle-treated group.

polygonumse negalense in Egypt (Nakanishi et al., 1995). The $2076 \mathrm{~A}$ was subsequently reported to have other bioactivities, such as radical scavenging and antifungal (Johann et al., 2012; Wang et al., 2012). The present study has provided compelling evidence that 2076A is a novel class of FXR agonist.

FXR plays critical roles in maintaining the homeostasis of bile acids, lipid, and glucose by regulating the transcription of 
A
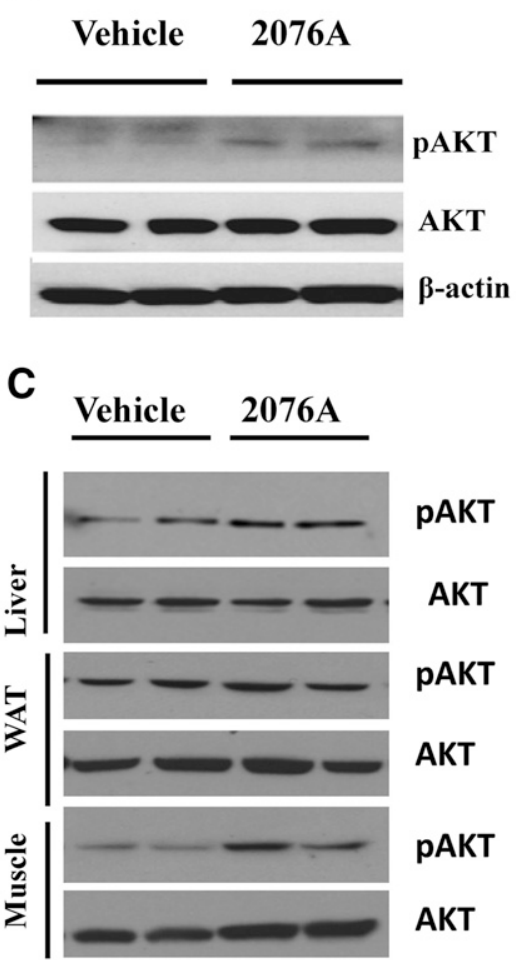

D

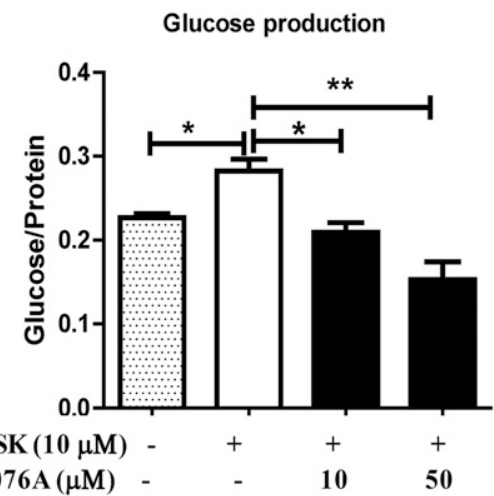

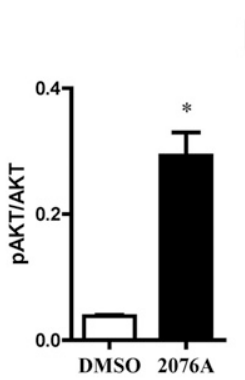

B

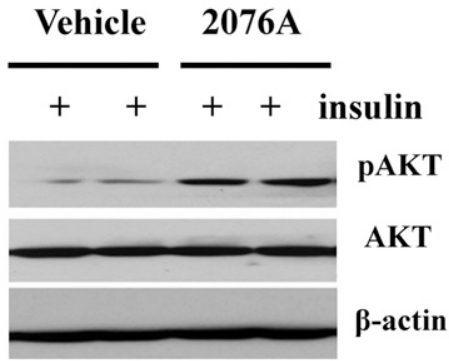

Liver

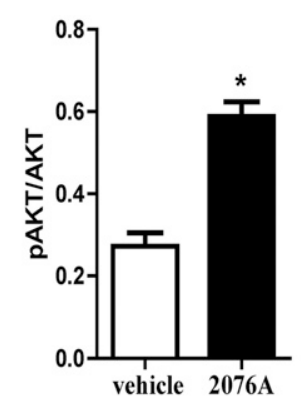

WAT

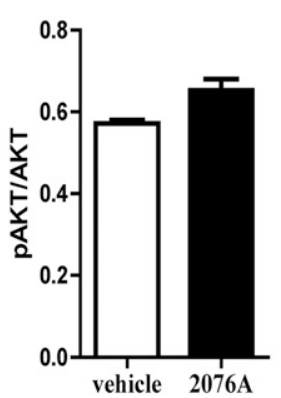

Muscle

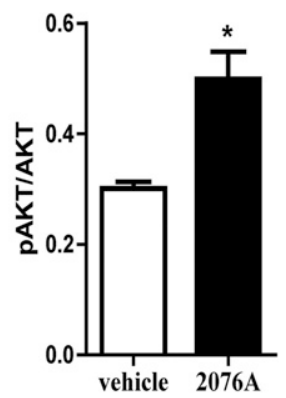

E

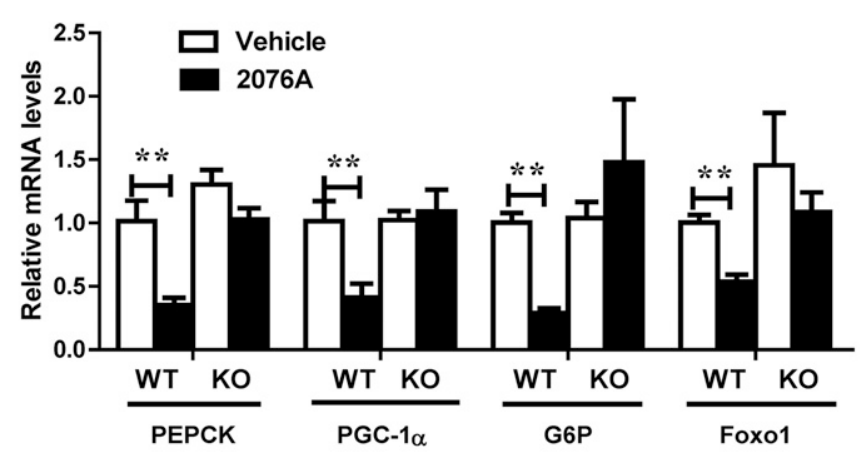

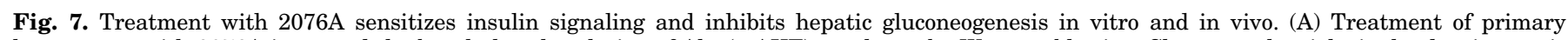

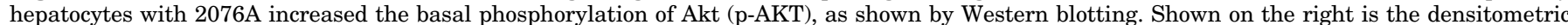

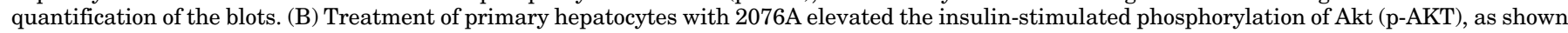

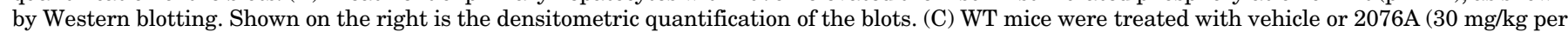

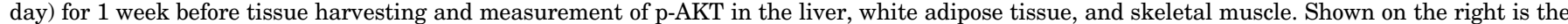

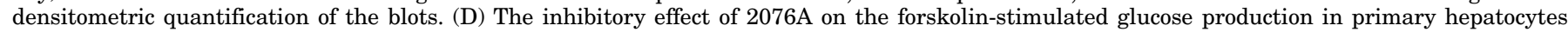

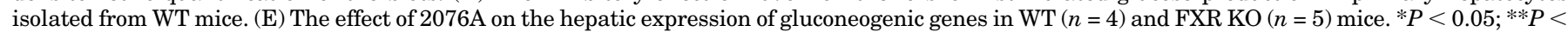
0.01 , compared with the vehicle-treated group.

genes involved in lipid and glucose homeostasis and inflammation. However, the metabolic benefits of FXR are not without controversies. For example, it has been reported that the HFD-fed FXR whole-body KO mice displayed metabolic improvement (Prawitt et al., 2011; Gonzalez et al., 2015), and glycine- $\beta$-muricholic acid, a bile acid derivative and FXR antagonist, exhibited metabolic benefits in diet-induced and genetic obese mice through intestine-selective FXR antagonism (Jiang et al., 2015). However, the majority of previous studies demonstrated the metabolic benefits of FXR agonists, such as PX-102 and obeticholic acid, in improving glucose homeostasis and lipid metabolism. PX-102, a derivative of
GW4064 with improved absorption, distribution, metabolism, and excretion (ADME) properties (Gege et al., 2014), is currently tested in a phase IIa study in patients with NAFLD (https://www.clinicaltrials.gov). Obeticholic acid (also known as 6-ECDCA and INT-767), a semisynthetic FXR agonist derived from CDCA, has been shown to have therapeutic benefits, including improving lipid and glucose homeostasis, anti-inflammation, and antifibrosis in the liver, kidney, and intestine (Cipriani et al., 2010; Mudaliar et al., 2013). Obeticholic acid was recently approved by the Food and Drug Administration for the treatment of primary biliary cirrhosis and became the first-in class FXR agonist drug (Trivedi et al., 
2016). In addition, obeticholic acid showed promising results in a phase IIb clinical trial in patients with type 2 diabetes, NAFLD, and nonalcoholic steatohepatitis (Mudaliar et al., 2013; Armstrong and Newsome, 2015). Consistent with these notions, the current study demonstrated that activation of FXR by 2076 A can relieve metabolic disorder in mice.

The FXR-dependent antiobesity and antisteatotic activity of 2076 A was consistent with previous reports that FXR agonists lowered plasma levels of cholesterol and triglyceride and decreased accumulation of fat in the liver (Liu et al., 2003; Zhang et al., 2006; Cipriani et al., 2010; Maneschi et al., 2013). The suppression of lipogenic genes in 2076A-treated WT mice was consistent with the observation that the expression of lipogenic genes was upregulated in FXR KO mice (Ma et al., 2006). The alleviation of hyperglycemia and hyperinsulinemia and improved insulin sensitivity in HFD-induced obese and diabetic mice by $2076 \mathrm{~A}$ were consistent with the report that FXR deficiency led to impaired glucose tolerance and insulin sensitivity in mice and rats (Ma et al., 2006). The inhibition of gluconeogenesis by $2076 \mathrm{~A}$ was also consistent with a previous report that FXR $\mathrm{KO}$ mice had elevated expression of gluconeogenic genes (Ma et al., 2006).

The 2076A is a selective FXR agonist, but has little activity on 15 other nuclear receptors, among which is the xenobiotic receptor CAR. We and others reported that activation of CAR inhibits obesity and relieves insulin resistance (Dong et al., 2009; Gao et al., 2009). The lack of CAR activation suggested that CAR does not contribute to the metabolic benefit of 2076A. The G protein-coupled bile acid receptor (TGR5) is a member of the $G$ protein-coupled receptor superfamily. Activation of TGR5 by bile acids or synthetic ligands has been shown to be beneficial in body weight maintenance and glucose metabolism (Chen et al., 2011; Wang et al., 2011). Our results showed that 2076A had little effect on the hepatic expression of TGR5 in vivo. Moreover, treatment of TGR5transfected cells with $2076 \mathrm{~A}$ failed to activate the cotransfected TGR5-responsive reporter gene pCRE-luc (data not shown). The 2076A is a nonbile acid compound, and its metabolic benefits were abolished in FXR KO mice. These results suggest that the metabolic benefits of 2076A are FXRdependent but TGR5-independent. FXR has also been reported to induce the expression of FGF21 in rats and HepG2 cells (Cyphert et al., 2012). It will be interesting to know whether the induction of FGF 21 by FXR is conserved in mice, and, if so, whether the induction of FGF21 contributes to the antiobesity effect of 2076A. There is also growing evidence that microbiome is an important contributor to NAFLD (Quigley et al., 2016), and FXR has been shown to impact gut microbiota (Gonzalez et al., 2016; Zhang et al., 2016). Future studies are necessary to determine whether $2076 \mathrm{~A}$ can alter the composition of microbiome.

In summary, we have discovered the natural product $2076 \mathrm{~A}$ as a new class of nonsteroidal FXR agonist with marked metabolic benefits. The distinct pharmacophore of 2076A provides much needed opportunities to target FXR for the treatment of NAFLD and associated metabolic syndrome.

\section{Authorship Contributions}

Participated in research design: Z. Zheng, Z. Zhao, Xie.

Conducted experiments: Z. Zheng, Z. Zhao, Lu, Shen, Jiang, Lin, An, Xie, Xu, Huang.

Performed data analysis: Z. Zheng, Z. Zhao, Xie.
Wrote or contributed to the writing of the manuscript: Z. Zheng, Z. Zhao, Shen, Sh. Li, Guo, So. Li, Zhang, Xie.

\section{References}

Ali AH, Carey EJ, and Lindor KD (2015) Recent advances in the development of farnesoid X receptor agonists. Ann Transl Med 3:5.

Armstrong MJ and Newsome PN (2015) Trials of obeticholic acid for non-alcoholic steatohepatitis. Lancet 386:28

Barthel A and Schmoll D (2003) Novel concepts in insulin regulation of hepatic gluconeogenesis. Am J Physiol Endocrinol Metab 285:E685-E692.

Boss O, Hagen T, and Lowell BB (2000) Uncoupling proteins 2 and 3: potential regulators of mitochondrial energy metabolism. Diabetes 49:143-156.

Chen A, Tang Y, Davis V, Hsu FF, Kennedy SM, Song H, Turk J, Brunt EM, Newberry EP, and Davidson NO (2013) Liver fatty acid binding protein (L-Fabp) modulates murine stellate cell activation and diet-induced nonalcoholic fatty liver disease. Hepatology 57:2202-2212.

Chen X, Lou G, Meng Z, and Huang W (2011) TGR5: a novel target for weight maintenance and glucose metabolism. Exp Diabetes Res 2011:853501.

Cipriani S, Mencarelli A, Palladino G, and Fiorucci S (2010) FXR activation reverses insulin resistance and lipid abnormalities and protects against liver steatosis in Zucker (fa/fa) obese rats. J Lipid Res 51:771-784.

Cyphert HA, Ge X, Kohan AB, Salati LM, Zhang Y, and Hillgartner FB (2012) Activation of the farnesoid $\mathrm{X}$ receptor induces hepatic expression and secretion of fibroblast growth factor 21. J Biol Chem 287:25123-25138.

Dong B, Saha PK, Huang W, Chen W, Abu-Elheiga LA, Wakil SJ, Stevens RD, Ilkayeva O, Newgard CB, Chan L, et al. (2009) Activation of nuclear receptor CAR ameliorates diabetes and fatty liver disease. Proc Natl Acad Sci USA 106 18831-18836.

Downes M, Verdecia MA, Roecker AJ, Hughes R, Hogenesch JB, Kast-Woelbern HR Bowman ME, Ferrer JL, Anisfeld AM, Edwards PA, et al. (2003) A chemical, genetic, and structural analysis of the nuclear bile acid receptor FXR. Mol Cell 11: 1079-1092.

Flatt B, Martin R, Wang TL, Mahaney P, Murphy B, Gu XH, Foster P, Li J, Pircher P, Petrowski M, et al. (2009) Discovery of XL335 (WAY-362450), a highly potent, selective, and orally active agonist of the farnesoid X receptor (FXR). J Med Chem 52:904-907.

Forman BM, Goode E, Chen J, Oro AE, Bradley DJ, Perlmann T, Noonan DJ, Burka LT, McMorris T, Lamph WW, et al. (1995) Identification of a nuclear receptor that is activated by farnesol metabolites. Cell 81:687-693.

Gao J, He J, Zhai Y, Wada T, and Xie W (2009) The constitutive androstane receptor is an anti-obesity nuclear receptor that improves insulin sensitivity. $J$ Biol Chem 284:25984-25992.

Gao J, Yan J, Xu M, Ren S, and Xie W (2015) CAR suppresses hepatic gluconeogenesis by facilitating the ubiquitination and degradation of PGC1 $\alpha$. Mol Endocrinol 29:1558-1570.

Gege C, Kinzel O, Steeneck C, Schulz A, and Kremoser C (2014) Knocking on FXR's door: the "hammerhead"-structure series of FXR agonists: amphiphilic isoxazoles with potent in vitro and in vivo activities. Curr Top Med Chem 14 2143-2158.

Gonzalez FJ, Jiang C, Bisson WH, and Patterson AD (2015) Inhibition of farnesoid X receptor signaling shows beneficial effects in human obesity. J Hepatol 62: $1234-1236$

Gonzalez FJ, Jiang C, and Patterson AD (2016) An intestinal microbiota-farnesoid X receptor axis modulates metabolic disease. Gastroenterology 151:845-859.

Goodwin B, Jones SA, Price RR, Watson MA, McKee DD, Moore LB, Galardi C, Wilson JG, Lewis MC, Roth ME, et al. (2000) A regulatory cascade of the nuclear receptors FXR, SHP-1, and LRH-1 represses bile acid biosynthesis. Mol Cell 6: $517-526$.

He J, Gao J, Xu M, Ren S, Stefanovic-Racic M, O'Doherty RM, and Xie W (2013) PXR ablation alleviates diet-induced and genetic obesity and insulin resistance in mice. Diabetes 62:1876-1887.

Hernandez R, Teruel T, and Lorenzo M (2001) Akt mediates insulin induction of glucose uptake and up-regulation of GLUT4 gene expression in brown adipocytes. FEBS Lett 494:225-231.

Jiang C, Xie C, Lv Y, Li J, Krausz KW, Shi J, Brocker CN, Desai D, Amin SG, Bisson $\mathrm{WH}$, et al. (2015) Intestine-selective farnesoid $\mathrm{X}$ receptor inhibition improves obesity-related metabolic dysfunction. Nat Commun 6:10166.

Johann S, Rosa LH, Rosa CA, Perez P, Cisalpino PS, Zani CL, and Cota BB (2012) Antifungal activity of altenusin isolated from the endophytic fungus Alternaria sp. against the pathogenic fungus Paracoccidioides brasiliensis. Rev Iberoam Micol 29: 205-209.

Lambert G, Amar MJ, Guo G, Brewer HB, Jr, Gonzalez FJ, and Sinal CJ (2003) The farnesoid X-receptor is an essential regulator of cholesterol homeostasis. J Biol Chem 278:2563-2570.

Li Y, Jadhav K, and Zhang Y (2013) Bile acid receptors in non-alcoholic fatty liver disease. Biochem Pharmacol 86:1517-1524.

Liu Y, Binz J, Numerick MJ, Dennis S, Luo G, Desai B, MacKenzie KI, Mansfield TA, Kliewer SA, Goodwin B, et al. (2003) Hepatoprotection by the farnesoid X receptor agonist GW4064 in rat models of intra- and extrahepatic cholestasis. J Clin Invest 112:1678-1687.

Loomba R and Sanyal AJ (2013) The global NAFLD epidemic. Nat Rev Gastroenterol Hepatol 10:686-690.

Lu TT, Makishima M, Repa JJ, Schoonjans K, Kerr TA, Auwerx J, and Mangelsdorf DJ (2000) Molecular basis for feedback regulation of bile acid synthesis by nuclear receptors. Mol Cell 6:507-515.

Ma K, Saha PK, Chan L, and Moore DD (2006) Farnesoid X receptor is essential for normal glucose homeostasis. J Clin Invest 116:1102-1109.

MacDougald OA and Lane MD (1995) Transcriptional regulation of gene expression during adipocyte differentiation. Annu Rev Biochem 64:345-373. 
Makishima M, Okamoto AY, Repa JJ, Tu H, Learned RM, Luk A, Hull MV, Lustig KD, Mangelsdorf DJ, and Shan B (1999) Identification of a nuclear receptor for bile acids. Science 284:1362-1365.

Maloney PR, Parks DJ, Haffner CD, Fivush AM, Chandra G, Plunket KD, Creech KL, Moore LB, Wilson JG, Lewis MC, et al. (2000) Identification of a chemical tool for the orphan nuclear receptor FXR. J Med Chem 43:2971-2974.

Maneschi E, Vignozzi L, Morelli A, Mello T, Filippi S, Cellai I, Comeglio P, Sarchielli E, Calcagno A, Mazzanti B, et al. (2013) FXR activation normalizes insulin sensitivity in visceral preadipocytes of a rabbit model of MetS. J Endocrinol 218 215-231.

Morris GM, Huey R, Lindstrom W, Sanner MF, Belew RK, Goodsell DS, and Olson AJ (2009) AutoDock4 and AutoDockTools4: automated docking with selective receptor flexibility. J Comput Chem 30:2785-2791.

Mudaliar S, Henry RR, Sanyal AJ, Morrow L, Marschall HU, Kipnes M, Adorini L, Sciacca CI, Clopton P, and Castelloe E, et al. (2013) Efficacy and safety of the farnesoid $X$ receptor agonist obeticholic acid in patients with type 2 diabetes and nonalcoholic fatty liver disease. Gastroenterology 145 : 574-582.e1.

Nakanishi S, Toki S, Saitoh Y, Tsukuda E, Kawahara K, Ando K, and Matsuda Y (1995) Isolation of myosin light chain kinase inhibitors from microorganisms: dehydroaltenusin, altenusin, atrovenetinone, and cyclooctasulfur. Biosci Biotechnol Biochem 59:1333-1335.

Parks DJ, Blanchard SG, Bledsoe RK, Chandra G, Consler TG, Kliewer SA, Stimmel JB, Willson TM, Zavacki AM, Moore DD, et al. (1999) Bile acids: natural ligands for an orphan nuclear receptor. Science 284:1365-1368.

Prawitt J, Abdelkarim M, Stroeve JH, Popescu I, Duez H, Velagapudi VR, Dumont J, Bouchaert E, van Dijk TH, Lucas A, et al. (2011) Farnesoid X receptor deficiency improves glucose homeostasis in mouse models of obesity. Diabetes 60 1861-1871.

Quigley EM, Abu-Shanab A, Murphy EF, Stanton C, and Monsour HP, Jr (2016) The metabolic role of the microbiome: implications for NAFLD and the metabolic syndrome. Semin Liver Dis 36:312-316.

Schmitt J, Kong B, Stieger B, Tschopp O, Schultze SM, Rau M, Weber A, Müllhaup B, Guo GL, and Geier A (2015) Protective effects of farnesoid X receptor (FXR) on hepatic lipid accumulation are mediated by hepatic FXR and independent of intestinal FGF15 signal. Liver Int 35:1133-1144.

Sinal CJ, Tohkin M, Miyata M, Ward JM, Lambert G, and Gonzalez FJ (2000) Targeted disruption of the nuclear receptor FXR/BAR impairs bile acid and lipid homeostasis. Cell 102:731-744

Trivedi PJ, Hirschfield GM, and Gershwin ME (2016) Obeticholic acid for the treatment of primary biliary cirrhosis. Expert Rev Clin Pharmacol 9:13-26.

Wang H, Chen J, Hollister K, Sowers LC, and Forman BM (1999) Endogenous bile acids are ligands for the nuclear receptor FXR/BAR. Mol Cell 3:543-553.

Wang QX, Bao L, Yang XL, Guo H, Yang RN, Ren B, Zhang LX, Dai HQ, Guo LD, and Liu HW (2012) Polyketides with antimicrobial activity from the solid culture of an endolichenic fungus Ulocladium sp. Fitoterapia 83:209-214.

Wang YD, Chen WD, Yu D, Forman BM, and Huang W (2011) The G-protein-coupled bile acid receptor, Gpbar1 (TGR5), negatively regulates hepatic inflammatory response through antagonizing nuclear factor $\kappa$ light-chain enhancer of activated $\mathrm{B}$ cells (NF-kB) in mice. Hepatology 54:1421-1432.

Zhang L, Xie C, Nichols RG, Chan SH, Jiang C, Hao R, Smith PB, Cai J, Simons MN and Hatzakis E, et al. (2016) Farnesoid X receptor signaling shapes the gut microbiota and controls hepatic lipid metabolism. mSystems 1:e00070-16.

Zhang S, Wang J, Liu Q, and Harnish DC (2009) Farnesoid X receptor agonist WAY362450 attenuates liver inflammation and fibrosis in murine model of non-alcoholic steatohepatitis. J Hepatol 51:380-388.

Zhang Y, Lee FY, Barrera G, Lee H, Vales C, Gonzalez FJ, Willson TM, and Edwards PA (2006) Activation of the nuclear receptor FXR improves hyperglycemia and hyperlipidemia in diabetic mice. Proc Natl Acad Sci USA 103:1006-1011.

Zheng ZH, Lu XH, Zhang H, Lv GP, He JG, Zhao BH, and Si SY (2010) Impacts of different promoters on the mammalian one-hybrid assay for detecting nuclear receptor agonists. Anal Bioanal Chem 396:1721-1730.

Address correspondence to: Dr. Wen Xie, Center for Pharmacogenetics and Department of Pharmaceutical Sciences, 306 Salk Pavilion, University of Pittsburgh, Pittsburgh, PA 15261. E-mail: wex6@pitt.edu 